\title{
Rectangular Ring Open-Ended Monopole Antenna for Mobile Dual-Band Operations
}

\author{
Joong Han Yoon ${ }^{1} \cdot$ Ryung Seo $\mathrm{Koo}^{2} \cdot$ Young Chul Rhee ${ }^{3}$
}

\begin{abstract}
This paper presents a novel design for a simple rectangular ring with an open-ended monopole antenna that is well suited to DCS/PCS/UMTS/WLAN applications for dual-band operations. A microstrip-fed rectangular monopole antenna is first designed and then modified to introduce the rectangular ring with an open-ended antenna and a rectangular slit in the ground plane. Prototypes of the proposed antenna were fabricated and tested. The antenna, resonating at 1,405 MHz and 4,840 MHz, has a $-10 \mathrm{~dB}$ impedance bandwidth of about 1,695 and 1,530 MHz (1,220 2,815 and $4,495 \sim 6,025 \mathrm{MHz}$ ), or about $79.06 \%$ and $29.09 \%$. The observed 2D radiation patterns and 3D gain performance of the antenna in the operation bands are discussed.
\end{abstract}

Key words: Ring Antenna with Open-Ended, DCS/PCS/UMTS/WLAN Antenna, Dual-Band Operation, Rectangular Slit in the Ground.

\section{Introduction}

The rapid progress in personal and computer communication technologies demands the integration of more than one communication system into a single compact module. This requirement needs compact multi-band planar antennas with good radiation pattern characteristics. The increasing demand for antennas with multi-band capabilities in modern wireless communication systems has attracted public attention. Several systems have been developed and implemented to cope with specific functions and applications, such as Bluetooth, WLAN, WiMAX, UWB, etc.

Printed monopole antennas have been used for many kinds of wireless devices because of their low cost, light weight, and ease of fabrication. Various kinds of multi-band antennas have been reported for WLAN, DCS 1,800, and IMT-2000 applications [1] [11]. In particular, several papers related to the study of rectangular, ring-shaped monopole antennas have proposed these types of devices [12] [15].

A microstrip line-fed ring antenna with a compact structure [12], however, can only be used for single-band operations. In our previous study [13], we discussed the use of a rectangular ring with an open-ended CPW-fed antenna for $2.4 / 5.2 \mathrm{GHz}$ operations. A CPW-fed, closed rectangular ring antenna with a vertical strip for WLAN operations was proposed [14] and a CPW-fed, folded monopole antenna with two symmetric strip arms was subsequently proposed for WLAN operations [15].

The present study investigates a novel design for a monopole antenna excited by a microstrip feed line for dual-band operations. The principle of dual-band operations is to introduce a rectangular ring with an openended antenna and a rectangular slit in the ground plane. Experimental results demonstrate that the impedance matching of the proposed antenna depends upon the dimensions of the rectangular slit in the ground plane. The parameters of the antenna are optimized, and the reflection characteristics are presented for a prototype suitable for wireless communication systems, the Digital Cellular System (DSC: 1,710 1,800 MHz) bands, the Personal Communication System (PSC: 1,850 1,990 MHz) bands, the Universal Mobile Telecommunication System (UMTS: $1,920 \sim 2,170 \mathrm{MHz}$ ) bands, and wireless local area networks (WLAN: 2,400 2,484 $\mathrm{MHz}$ and 5,150 5,975 $\mathrm{MHz}$ ). The detailed design and the results of experiments using the proposed monopole antenna are pre-

Manuscript received November 20, 2012 ; Revised December 21, 2012 ; Accepted January 2, 2013. (ID No. 20121120-027J)

${ }^{1}$ Dept. of Electric Engineering, Silla University, Busan, Korea.

${ }^{2}$ Defense Agency for Technology and Quality, Korea.

${ }^{3}$ Dept. of Information \& Communication Engineering, Kyungnam University, Changwon, Korea.

Corresponding Author : Young Chul Rhee (e-mail : micropt@kyungnam.ac.kr)

This is an Open-Access article distributed under the terms of the Creative Commons Attribution Non-Commercial License (http://creativecommons.org/licenses/ by-nc/3.0) which permits unrestricted non-commercial use, distribution, and reproduction in any medium, provided the original work is properly cited. 
sented and discussed.

\section{II . Antenna Design}

Fig. 1 shows the geometry of the proposed DCS/ PCS/UMTS/WLAN monopole antenna designed to facilitate dual-band frequency operations. The design incorporates a total size of the substrate (blue) of $30 \times 50 \mathrm{~mm}^{2}$ $\left(W_{10} \times L_{1}\right)$. The proposed antenna is fabricated on one side of an inexpensive FR4 substrate with a relative permittivity of 4.4 and a substrate thickness $(h)$ of 1.0 $\mathrm{mm}$. The radiating element (yellow) of the proposed antenna, with dimensions of $29.6 \times 28.0 \mathrm{~mm}^{2}\left(W_{1} \times L_{5}\right)$, is a symmetrical rectangular ring, open-ended antenna with a width $\left(L_{6}\right)$ of $3 \mathrm{~mm}$ for design convenience. The ground plane (green), whose size is $29.6 \times 18.5 \mathrm{~mm}^{2}\left(\left(2 W_{8}+W_{9}\right)\right.$ $\left.\times L_{2}\right)$, is placed on the other side of the substrate. This design has an open-ended rectangular ring to provide resonance for $2,400 \mathrm{MHz}$ bands. A $50 \Omega$ microstrip feed line, $W_{7}=2 \mathrm{~mm}$, is used for central feeding of the antenna from the bottom edge of the symmetrical rectangular ring, open-ended antenna. Good impedance matching and wide bandwidth for operating frequencies are obtained by introducing a rectangular slit, $4 \times 9.5 \mathrm{~mm}^{2}$ $\left(W_{9} \times L_{3}\right)$, in the ground plane.

The rectangular slit is located centrally on top of the ground plane. The antenna was analyzed using Ansoft's High Frequency Structure Simulator (HFSS) simulation package in order to study the effect of the design parameters on its characteristics [16].

2-1 Effect of the Gap between the Ground Plane and the Rectangular Ring, Open-Ended Antenna, $L_{4}$

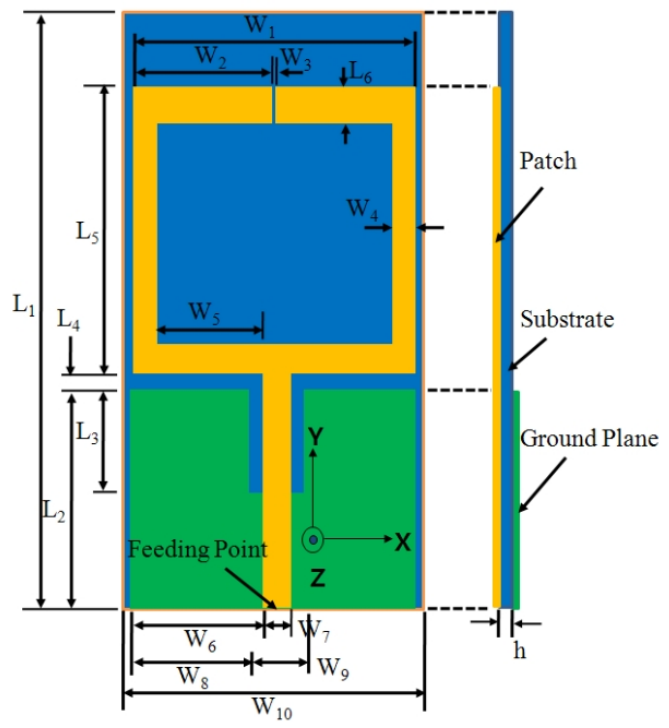

Fig. 1. Configuration of the rectangular ring, open-ended monopole antenna.

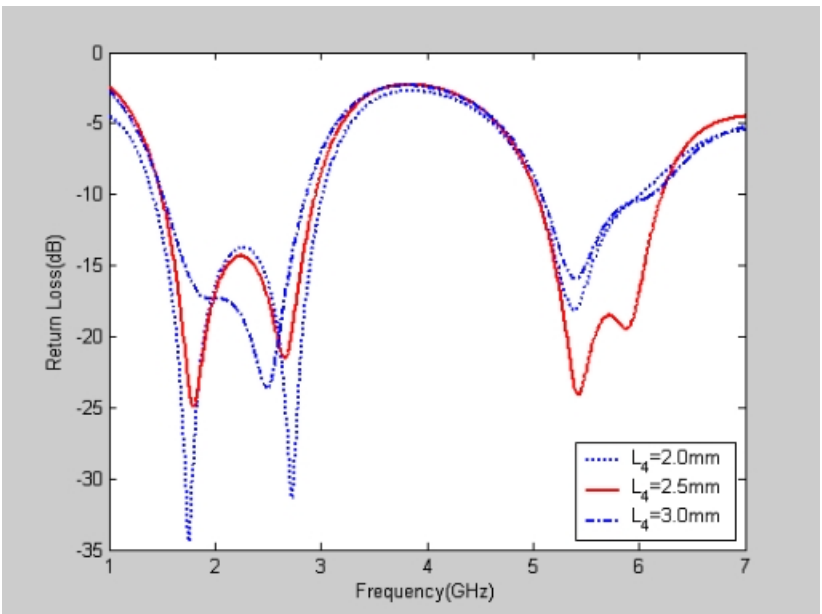

Fig. 2. Simulated return loss of the proposed antenna with different values, $L_{4}$.

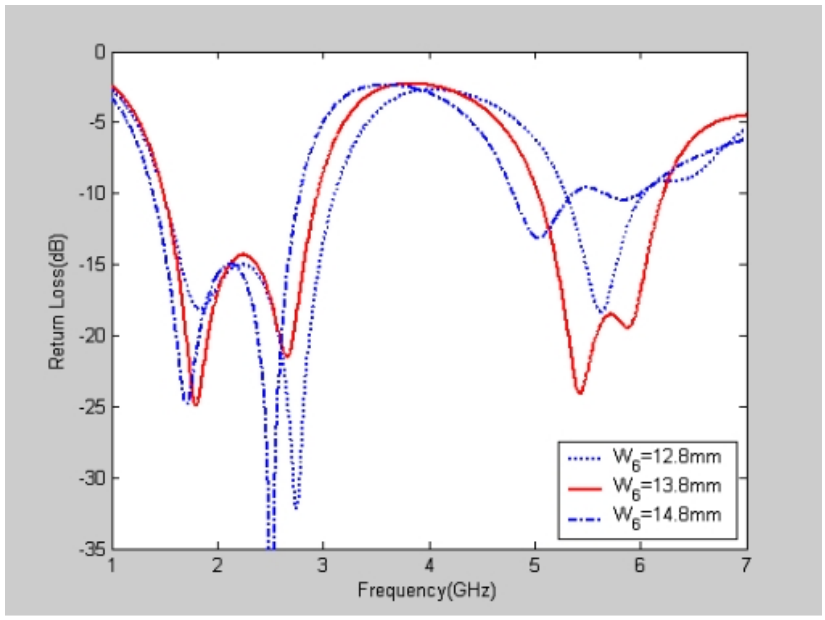

Fig. 3. Simulated return loss of the proposed antenna with different values, $W_{4}$.

Fig. 2 shows the return loss for the different values of the length of $L_{4}$, which is the length of the gap between the ground plane and the rectangular ring, openended antenna. For the DCS/PCS/UMTS/WLAN bands, the figure shows that the impedance bandwidth and return loss characteristics changed when $L_{4}$ varied from 2.0 to $3.0 \mathrm{~mm}$. The figure also shows, however, that when $L_{4}$ is $2.5 \mathrm{~mm}$, the return loss characteristics for the $5,000 \mathrm{MHz}$ WLAN bands are better than they are when $L_{4}$ is $2.0 \mathrm{~mm}$ and $3.0 \mathrm{~mm}$. Thus, for optimal DCS/ PCS/UMTS/ WLAN operation, $L_{4}$ was set at $2.5 \mathrm{~mm}$.

\section{2-2 Effect of the Ground Plane, $W_{6}$}

Fig. 3 shows the return loss for different values of the length of $W_{6} . W_{6}$ is the length of the rectangular ring, open-ended antenna. For the DCS/PCS/UMTS/WLAN bands, the figure shows that the impedance bandwidth and 


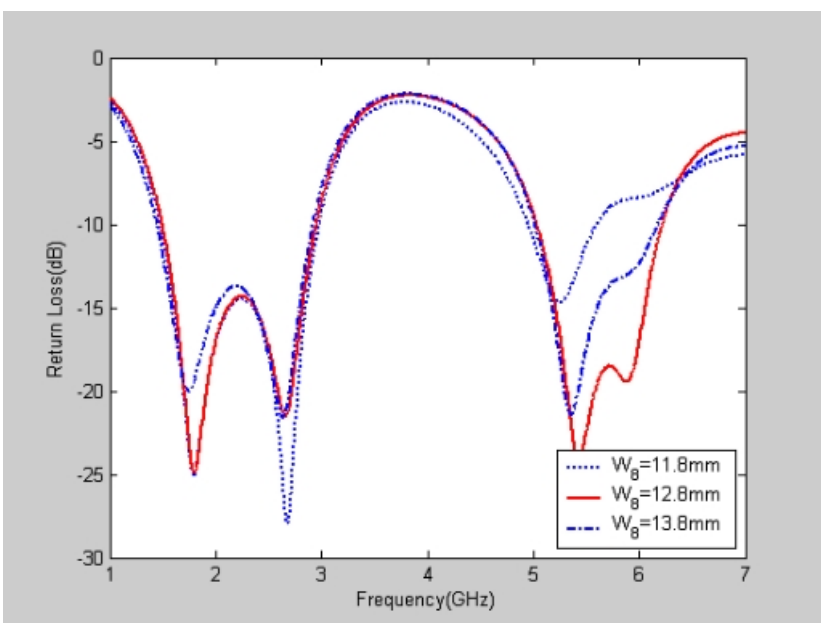

Fig. 4. Simulated return loss of the proposed antenna with different values, $W_{8}$.

return loss characteristics changed when $W_{6}$ was varied from 12.8 to $14.8 \mathrm{~mm}$. The figure also shows, however, that when $W_{6}$ is $13.8 \mathrm{~mm}$, the return loss characteristics for the 5,000 MHz WLAN bands are better than when $W_{6}$ is $12.8 \mathrm{~mm}$ and $14.8 \mathrm{~mm}$. Thus, for optimal DCS/ PCS/UMTS/WLAN operation, $W_{6}$ was set at $13.8 \mathrm{~mm}$.

\section{2-3 Effect of the Ground Plane, $W_{8}$}

Fig. 4 shows the return loss for different values of the width of $W_{8}$, which is the width of the ground plane. In the DCS/PCS/UMTS/2,400 MHz WLAN bands, the Fig. shows that the impedance bandwidth and return loss characteristics did not change when $W_{8}$ was varied from 11.8 to $13.8 \mathrm{~mm}$. For the $5,000 \mathrm{MHz}$ bands, the figure shows that the impedance bandwidth and return loss characteristics changed when $W_{8}$ was varied from 11.8 to $13.8 \mathrm{~mm}$. The figure also shows that when $W_{8}$ is 12.8 $\mathrm{mm}$, the return loss characteristics for the $5 \mathrm{GHz}$ bands are better than when $W_{8}$ is $11.8 \mathrm{~mm}$ and $13.8 \mathrm{~mm}$. Thus, for optimal DCS/PCS/UMTS/WLAN operation, $W_{8}$ was set at $12.8 \mathrm{~mm}$.

\section{2-4 Effect of the Rectangular Slit in the Ground Plane}

Dual-band DCS/PCS/UMTS/WLAN operation was achieved by introducing a rectangular slit in the ground plane, in order to alter the input impedance characteristics.

Fig. 5 shows the return loss with and without a slit in the ground plane. The Fig. shows that the resonant frequency was not generated in the $5,000 \mathrm{MHz}$ bands, and that the impedance bandwidth and return loss characteristics worsened in the absence of a rectangular slit in the ground plane. This indicates that the return loss

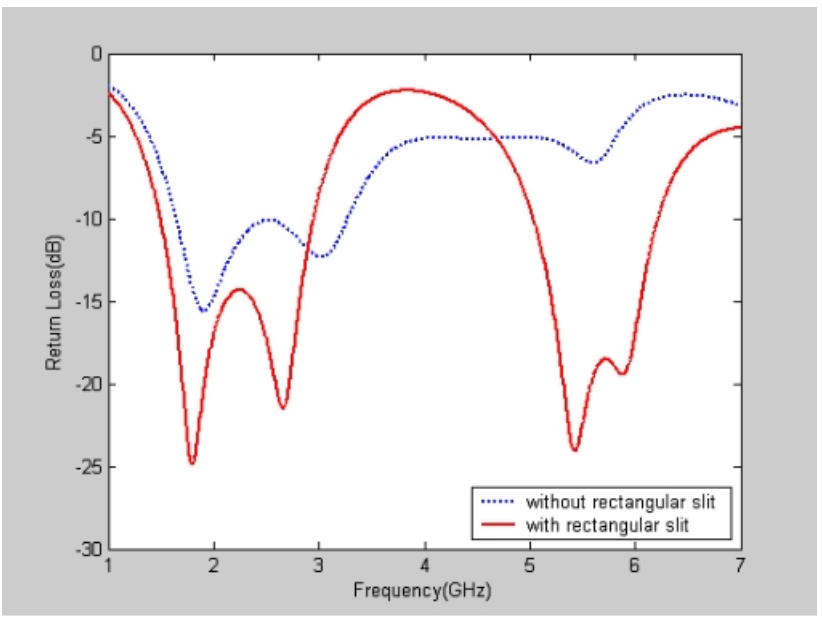

Fig. 5. Simulated return loss of the proposed antenna with and without a rectangular slit in the ground plane.

of the proposed antenna depends on this rectangular slit. In particular, the return loss characteristics of the proposed antenna in $5,000 \mathrm{MHz}$ bands heavily depended on this slit. The optimal values of the rectangular slit width $\left(W_{9}\right)$ and length $\left(L_{3}\right)$ were determined. To design a dualband DCS/PCS/UMTS/WLAN antenna, $W_{9}$ was set at $4.0 \mathrm{~mm}$, and $L_{3}$ was set at $9.5 \mathrm{~mm}$.

The proposed antenna structure has several design parameters that can handle the resistance and reactance

Table 1. Parameters of the proposed antenna.

\begin{tabular}{|c|c|c|c|c|c|}
\hline $\begin{array}{c}\text { Parame- } \\
\text { ters }\end{array}$ & $\begin{array}{c}\text { Unit } \\
{[\mathrm{mm}]}\end{array}$ & $\begin{array}{c}\text { Parame- } \\
\text { ters }\end{array}$ & $\begin{array}{c}\text { Unit } \\
{[\mathrm{mm}]}\end{array}$ & $\begin{array}{c}\text { Parame- } \\
\text { ters }\end{array}$ & $\begin{array}{c}\text { Unit } \\
{[\mathrm{mm}]}\end{array}$ \\
\hline$W_{1}$ & 29.6 & $W_{7}$ & 2.0 & $L_{3}$ & 9.5 \\
\hline$W_{2}$ & 14.6 & $W_{8}$ & 12.8 & $L_{4}$ & 2.5 \\
\hline$W_{3}$ & 2.0 & $W_{9}$ & 4.0 & $L_{5}$ & 28.0 \\
\hline$W_{4}$ & 2.0 & $W_{10}$ & 30.0 & $L_{6}$ & 3.0 \\
\hline$W_{5}$ & 11.8 & $L_{1}$ & 50.0 & $h$ & 1.0 \\
\hline$W_{6}$ & 3.0 & $L_{2}$ & 18.5 & & \\
\hline
\end{tabular}

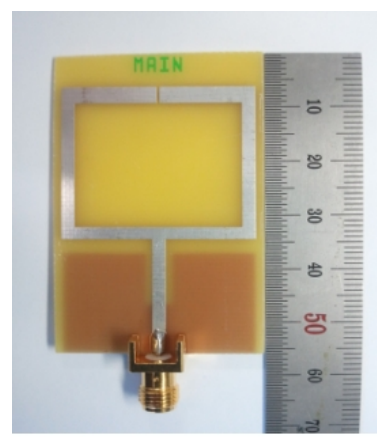

(a) Front view

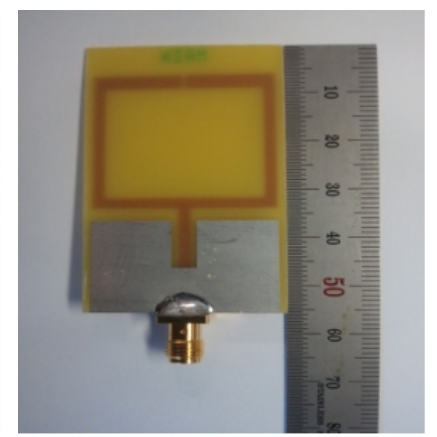

(b) Back view
Fig. 6. Prototype of the proposed dual-band antenna. 
of the antenna input impedance. As such, the dimensions of the proposed antenna were set as shown in Table 1 .

A prototype of the proposed antenna was fabricated with these design parameters, and is shown in Fig. 6(a) and (b).

\section{Measurement}

The measured and simulated return losses of the proposed antenna are depicted in figure 7. The frequency response of the return loss of the proposed antenna was measured using an Anritsu MS4644A vector network analyzer at Silla University. The figure shows similar tendencies between both measured and simulated results, but a slight difference in the actual values. This is probably a result of the influence of the coaxial connector that was connected to the patch radiating patch and that was not considered in the simulation. The slight difference is probably due to the influence of the cable that was connected to the proposed antenna during the measurement procedure, which was not considered in the simulation. Differences in relative permittivity may also have been involved.

Two resonant modes are excited at about 1,405 and 4,840 $\mathrm{MHz}$ with wide impedance bandwidths. The lowest resonant mode has a $10 \mathrm{~dB}$ impedance bandwidth of $1,695 \mathrm{MHz}(1,220 \sim 2,815 \mathrm{MHz})$, which covers the DCS/PCS/UMTS/2,400 MHz WLAN bands. The second resonant mode has an impedance bandwidth of 1,530 $\mathrm{MHz}(4,495 \sim 6,025 \mathrm{MHz})$, which satisfies the required bandwidth of the 5,200/5,800 MHz WLAN bands. Clearly, the design prototype of the proposed antenna has sufficient bandwidth to cover the needs of the DCS/ PCS/UMTS/2,400 MHz WLAN bands and 5,000 MHz WLAN bands $(1,710 \sim 2,484$ and $5,150 \sim 5,975 \mathrm{MHz}$,

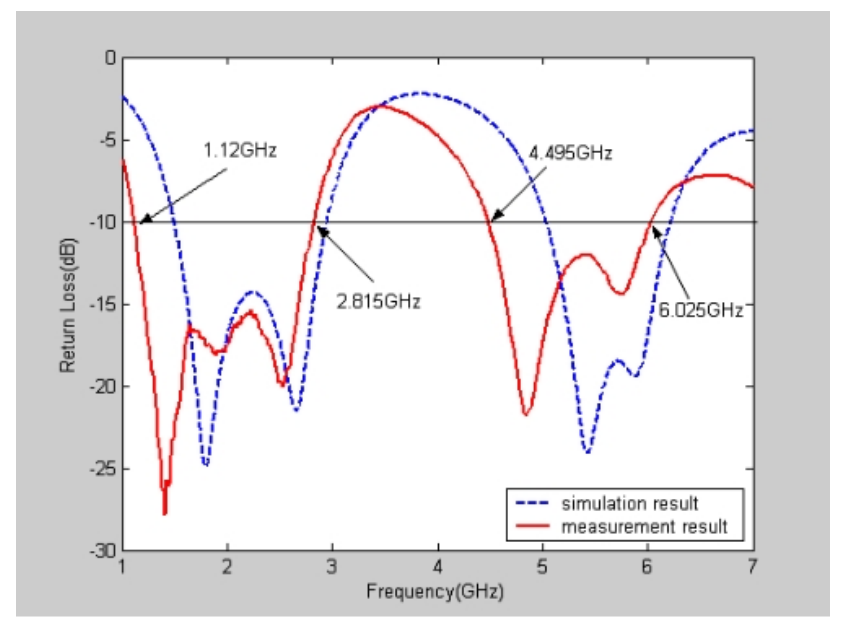

Fig. 7. Simulated and measured return loss vs. the frequencies of the proposed antenna.

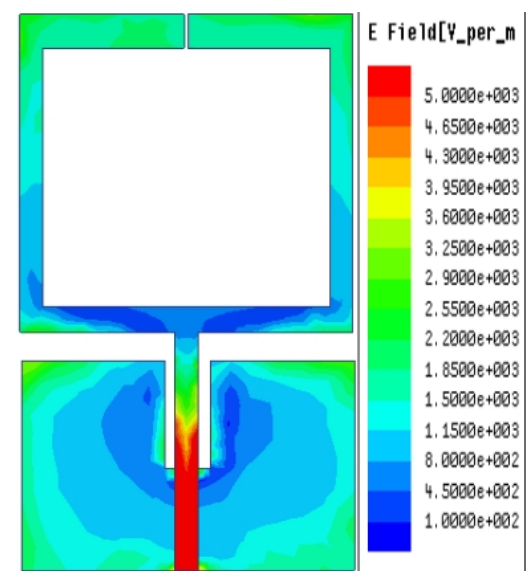

(a) $1.78 \mathrm{GHz}$

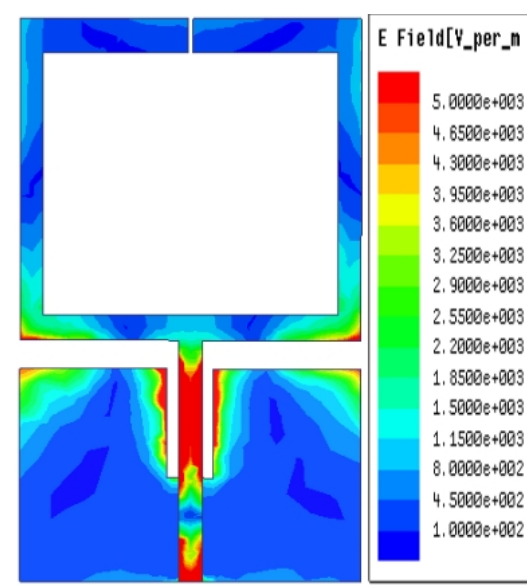

(b) $5.5 \mathrm{GHz}$

Fig. 8. Surface current distributions.

respectively).

Theoretically, HFSS was used to evaluate and verify the two resonant frequencies, 1,780 and 5,500 $\mathrm{MHz}$, which mainly depended on the lengths of the rectangular ring, open-ended antenna, and the rectangular slit in the ground plane. As expected, the different surface currents were clearly excited by the 1,780 and $5,500 \mathrm{MHz}$ frequencies. Figs. 8(a) and (b) show the surface current density excitations along the rectangular ring, open-ended antenna, and the rectangular slit in the ground plane in the cases of the two resonant frequencies, 1,780 and 5,500 MHz, respectively. As shown in Fig. 8(a), the surface current density excitations of the DCS/PCS/ UMTS/2,400 MHz WLAN bands along the rectangular ring, open-ended antenna were observed when the resonant frequency was $1,780 \mathrm{MHz}$. This implies that the DCS/PCS/UMTS/2,400 MHz WLAN band excitation arises mainly because of the length of the rectangular ring, open-ended antenna. As shown in Fig. 8(b), however, larger surface current densities flowed around the rectangular slit in the ground plane when the resonant frequency was 5,500 MHz. This implies that the 5,000 
$\mathrm{MHz}$ WLAN band excitation is mainly due to the rectangular slit in the ground plane.

Fig. 9 shows the measured $2 \mathrm{D}$ far-field radiation patterns in the E-plane (x-z plane) and $\mathrm{H}$ plane (y-z plane). Figs. $9(\mathrm{a}) \sim(\mathrm{d})$, and $(\mathrm{e})$ show the $2 \mathrm{D}$ radiation patterns at $1,800,2,000,2,400,5,300$, and 5,700 $\mathrm{MHz}$, respectively. Based on these radiation patterns, the pro-

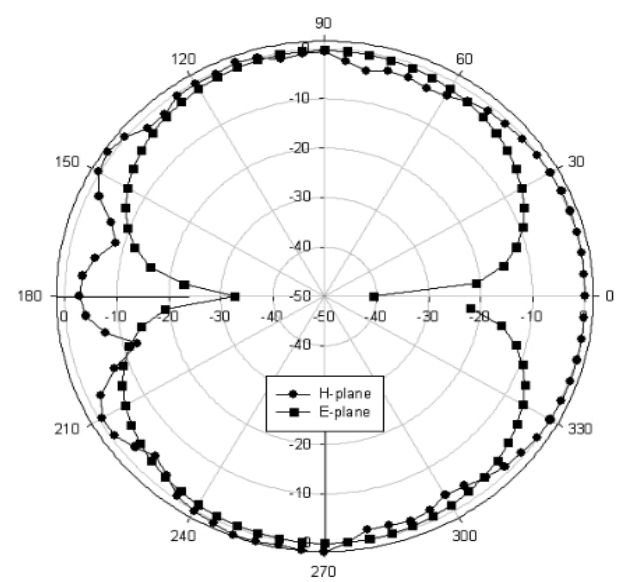

(a) $1,800 \mathrm{MHz}$

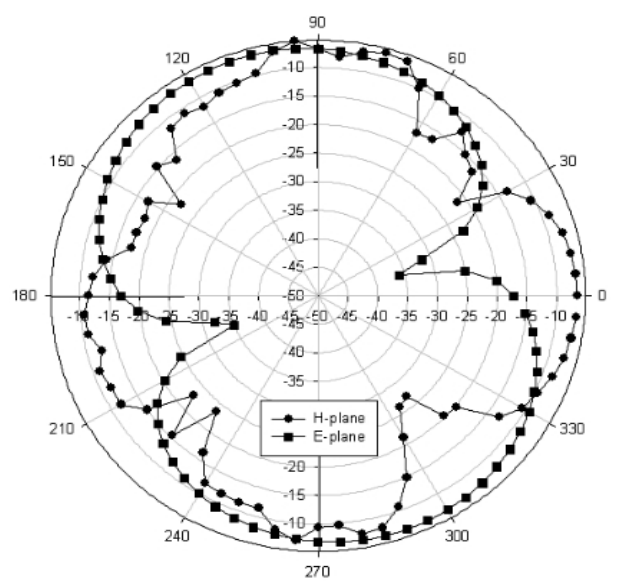

(c) $2,400 \mathrm{MHz}$ posed antenna displays omnidirectional radiation characteristics in the H-plane, and monopole-like radiation pattern characteristics in the E-plane at the considered frequencies.

Figs. 10(a), (b), and (c) show the 3D measured antenna peak and average gain for the frequencies across the DCS/PCS/UMTS/WLAN bands. The DCS/PCS/UMTS

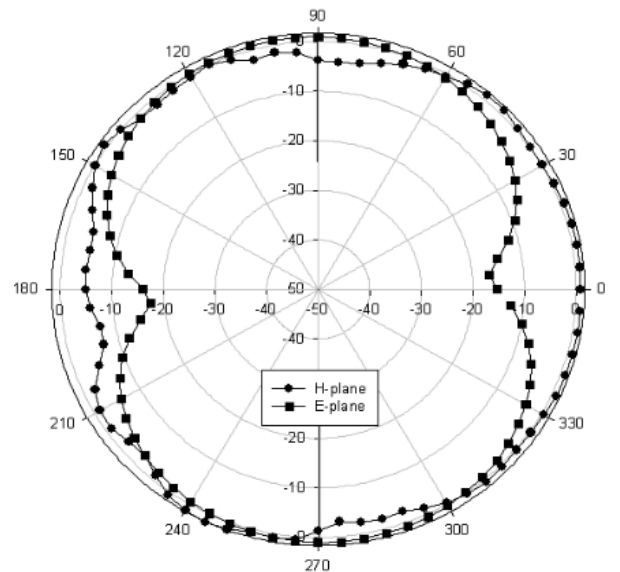

(b) $2,000 \mathrm{MHz}$

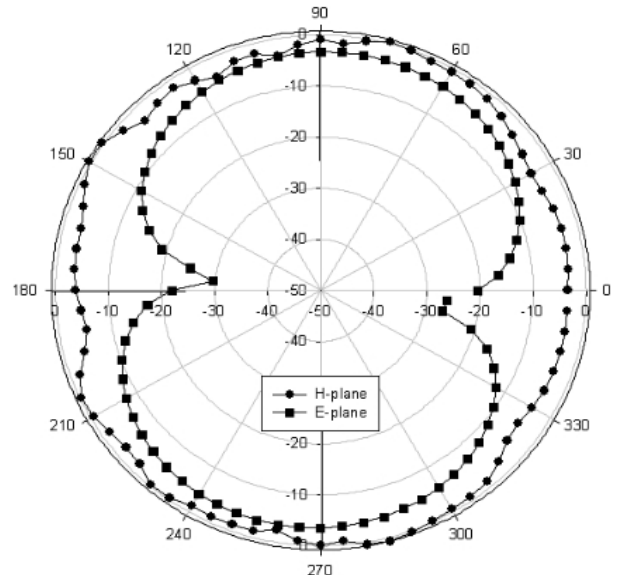

(d) $5,300 \mathrm{MHz}$

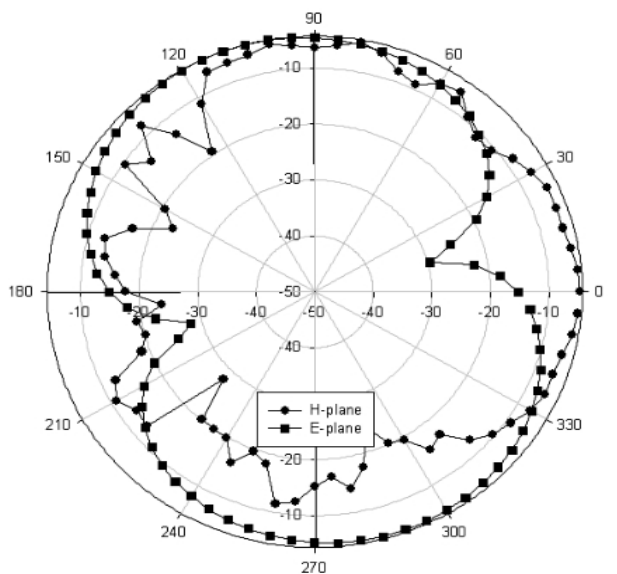

(e) $5,700 \mathrm{MHz}$.

Fig. 9. Radiation patterns of the proposed antenna at operating frequencies in the E-plane and H-plane. 


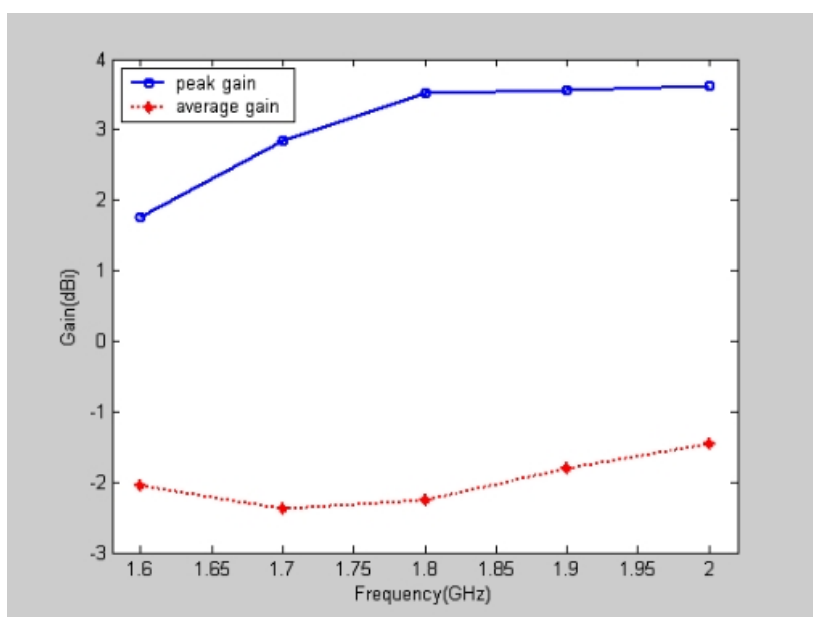

(a) DCS/PCS/UMTS bands

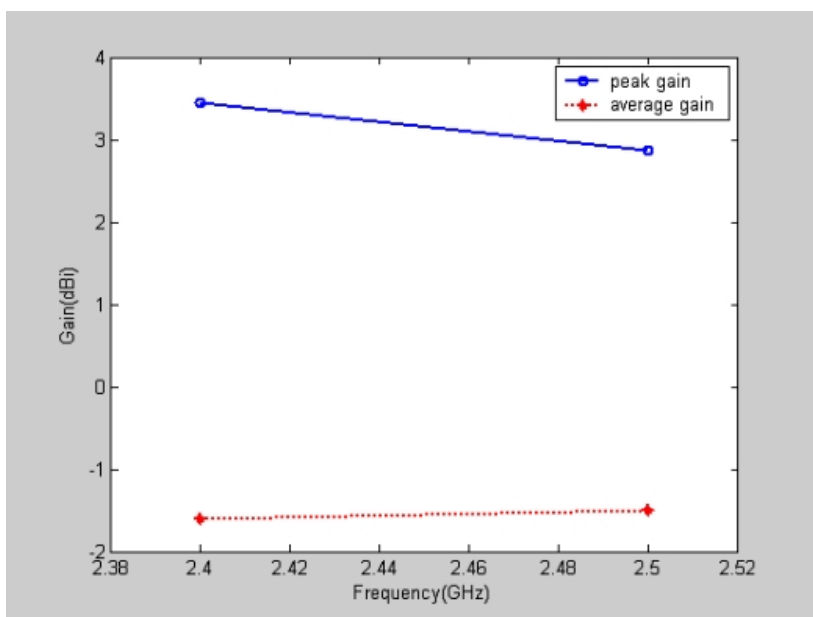

(b) 2,400 MHz WLAN bands

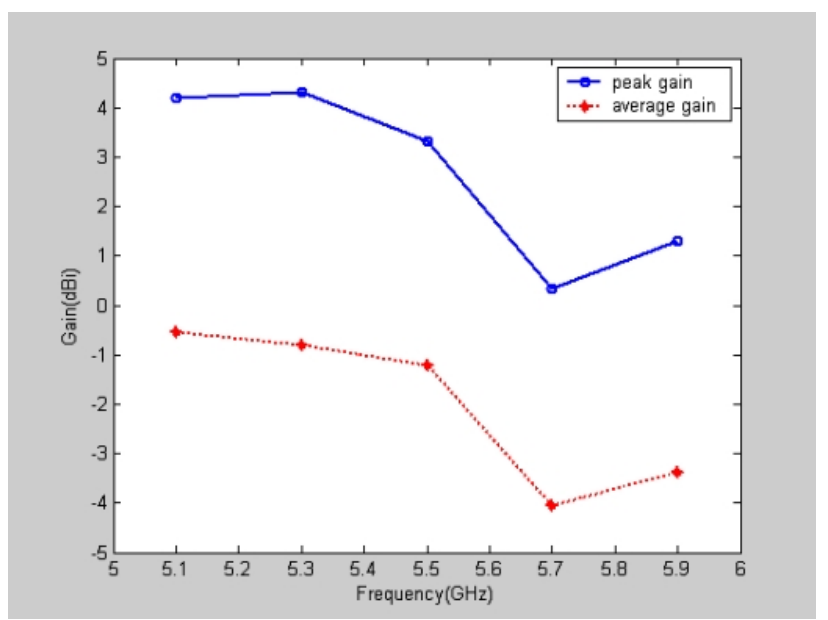

(b) 5,000 MHz WLAN bands

Fig. 10. Measured antenna peak and average gains for the following operating frequencies.

bands had an antenna peak gain level of about 1.76 $3.63 \mathrm{dBi}$ [Fig. 10(a)], the 2,400 MHz WLAN bands, about 2.86 3.45 dBi [Fig. 10(b)], and the 5,000 MHz
WLAN bands, about $0.34 \sim 4.30 \mathrm{dBi}$ [Fig. 10(c)]. The DCS/PCS/UMTS bands had an antenna average gain level of about $-2.37 \sim-1.46 \mathrm{dBi}$ [Fig. 10(a)], the 2,400 $\mathrm{MHz}$ WLAN bands, about $-1.61 \sim-1.50 \mathrm{dBi}$ [Fig. $10(\mathrm{~b})]$, and the 5,000 $\mathrm{MHz}$ WLAN bands, about -4.06 $\sim-0.53 \mathrm{dBi}$ [Fig. 10(c)]. The 3D maximum peak gain was $2.85 \mathrm{dBi}$; at $1,700 \mathrm{MHz}, 2.884 \mathrm{dBi}$; and at 1,900 $\mathrm{MHz}, 3.55 \mathrm{dBi}$. The 3D maximum peak gain was 3.45 $\mathrm{dBi}$; at 2,400 MHz, $2.884 \mathrm{dBi}$; and at 2,500 MHz, 2.86 $\mathrm{dBi}$. The 3D maximum peak gain was $3.45 \mathrm{dBi}$; at 5,300 $\mathrm{MHz}, 4.30 \mathrm{dBi}$; and at 5,700 $\mathrm{MHz}, 0.34 \mathrm{dBi}$.

\section{Conclusion}

A planar, dual-band monopole antenna covering DCS/ PCS/UMTS/WLAN bands is presented in this study. The use of a rectangular ring, an open-ended antenna, and a rectangular slit in the ground plane provided the impedance characteristics needed to meet the requirements of DCS/PCS/UMTS/WLAN bands and to facilitate dual-band frequency operations. Various parameters of the proposed antenna were optimized through simulation, and prototyped according to the optimized geometry. A prototype capable of generating two resonant modes to cover DCS/PCS/UMTS/WLAN systems was then tested. The measured $-10 \mathrm{~dB}$ impedance bandwidths were $79.06 \%(1.22 \sim 2.815,1,695 \mathrm{MHz})$ and 29.09 $\%(4.495 \sim 6.025 \mathrm{GHz}, 1,530 \mathrm{MHz})$. The proposed antenna, which provides nearly omnidirectional radiation pattern characteristics for frequencies over the DCS/PCS/ UMTS/WLAN bands, showed a measured peak gain varying between 0.34 and $4.30 \mathrm{dBi}$.

This research was financially supported by the Ministry of Education, Science, and Technology (MEST) and the National Research Foundation of Korea (NRF) through the Human Resource Training Project for Regional Innovation.

\section{References}

[1] R. K. Raj, M. Joseph, B. Paul, and P. Mohanan, "Compact planar multiband antenna for GPS, DCS, 2.4/5.8 GHz WLAN application," IEE Electron Letters, vol. 41, no. 6, pp. 291-293, Mar. 2005.

[2] M. Joseph, R. K. Raj, M. N. Suma, and P. Mohanan, "Compact dual band antenna for DCS/2.4 GHz WLAN application," Microwave and Optical Technology Letters, vol. 48, no. 5, pp. 854-859, May 2006.

[3] M. N. Sum, R. K. Raj, M. Joseph, P. C. Bybi, and 
P. Mohanan, "A compact dual band planar branched monopole antenna for DCS/2.4 GHz WLAN application," IEEE Antenna Wireless Component Letters, vol. 16, no. 5, pp. 275-277, May 2006.

[4] C. N. Chiu, H. R. Chen, "A compact and wideband balanced-fed triangular monopole antenna for DCS/ PCS/UMTS/WLAN/WiMAX applications," Microwave and Optical Technology Letters, vol. 50, no. 4, pp. 971-974, Apr. 2008.

[5] H. Rmili, J. M. Floch, "Design of a dual band V shaped monopole antenna for DCS/2.4 GHz WLAN, operation," Microwave and Optical Technology Letters, vol. 50, no. 9, pp. 2615-2617, 2008.

[6] G. Augustin, P. C. Bybi, V. P. Sarin, P. Mohanan, and C. K. Vasudevan, "A compact dual band planr antenna for DCS-1900/PCS/PHS, WCDMAA/IMT2000, and WLAN application," IEEE Antenna Wireless Propagation Letters, vol. 7, pp. 108-111, May 2008.

[7] J. F. Huang, M. T. Wu, and J. Y. Wen, "A compact tripe band antenna design UMTS, WLAN and WiMAX applications," Microwave and Optical Technology Letters, vol. 51, no. 9, pp. 2207-2212, Sep. 2009.

[8] L. Chen, X. W. Shi, T. L. Zhang, and Y. Song, "Compact CPW-fed triple band monopole antenna for PCS and 2.4/5 GHz WLAN application," Microwave and Optical Technology Letters, vol. 51, no. 10, pp. 2495-2498, Oct. 2009.

[9] W. C. Liu, P. W. Chen, and C. C. Liu, "Triple band planar monopole antenna for DMB/WLAN applications," Journal of Electromagnetic Waves and Applications, vol. 24, no. 5, pp. 653-661, 2010.

\section{Joong Han Yoon}

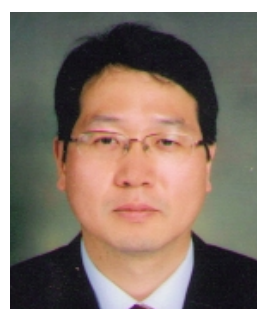

received his B.S., M.S. and Ph. D. degrees in electronics engineering from Inha University, Incheon, South Korea, in 1994, 1996, and 2003, respectively. From 2003, he has been the Post Doc. in the INHA University. From November 2004, to October 2005, he has been Post Doc. in Yokohama National University, Yokohama, Japan. From November 2005, to August 2008, he has been Senior Engineer of Samsung Electro-Mechanics, Suwon, Gyeonggi-do. From September 2008, he has been a faculty of Dept. of Electronics engineering, Silla University, Busan, South Korea. His research interests include mobile antenna, RFID, Digital.
[10] J. Y. Pang, S. Q. Xiao, S. T. Chen, and B. Z. Wang, "Compact and wideband PIFA for DCS/PCS/UMTS/WLAN communication system," Microwave and Optical Technology Letters, vol. 52, no. 5, pp. 10971100, May 2010.

[11] C. Mahatthanajatuphat, N. Wongsin, and P. Akkaraekthain, "A multiband monopole antenna with modified fractal loop parasitic for DCS 1800, WLAN, WiMAX, and IMT advanced system," IEICE Transactions on Communications, vol. E95.B, no. 1, pp. 27-33, Jan. 2012.

[12] W. C. Lin, "Compact microstrip-fed ring monopole antenna with tuning strip for $5 \mathrm{GHz}$ WLAN operation," IEE Electron Letters, vol. 41, no. 15, pp. 831-832, Jul. 2005.

[13] J. H. Yoon, "Fabrication and measurement of rectangular ring with open ended CPW-fed monopole antenna for 2.4/5.2 GHz WLAN operation," Microwave and Optical Technology Letters, vol. 48, no. 8, pp. 1480-1483, Aug. 2006.

[14] L. Zhang, Y. C. Jiao, G. Zhao, Y. Song, and F. S. Zhang, "Broadband dual band CPW-fed closed rectangular ring monopole antenna with a vertical strip for WLAN operation," Microwave and Optical Technology Letters, vol. 50, no. 7, pp. 1929-1931, Jul. 2008.

[15] Y. Seo, J. Jung, H. Lee, and Y. Lim, "Modified dual monopole antenna for WLAN operation," Microwave and Optical Technology Letters, vol. 53, no. 12, pp. 2768-2770, Dec. 2011.

[16] Ansoft High Frequency Structure Simulator, (HFSS) Version 12.0, Ansoft Corporation, 2010.

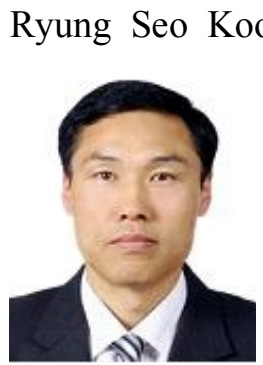

received the M.S. degrees in Information and Communication Engineering at Kyungnam University, Korea, in 2010 and $\mathrm{PhD}$ study from 2011 to the present at IT Convergence in Kyungnam University. From 1989 until now served as a senior researcher at Defense Agency for Technology and Quality Interested in: RF, Radar System Integration. 


\section{Young Chul Rhee}

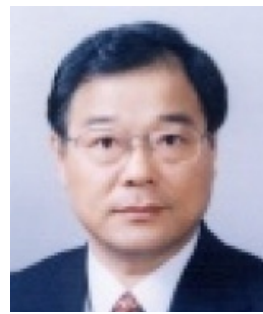

received the M.E. and Ph.D. degrees in electronics engineering from Yonsei University and Ajou University, Korea, in 1978 and 1990, respectively. From 1978 to 1981, he has been Korea Naval Academy as a full time instructor. And from 1981 to now, he is a Professor in Information and Communication Engineering at the Kyungnam University, Korea. His main research area includes solid state microwave amplifier and solid state radar systems, mobile communications RF modules. He is a member of IEEK, KICS, IEEE. 